\title{
Pensamento algébrico na formação inicial de professores ${ }^{1}$
}

\section{Algebraic thinking in initial teacher education}

\author{
João Pedro da Ponte ${ }^{2}$ \\ Neusa Branco ${ }^{3}$
}

\begin{abstract}
RESUMO
Este artigo descreve uma experiência de formação inicial orientada para o desenvolvimento do pensamento algébrico de educadores de infância e de futuros professores dos primeiros anos, realizada ao longo de um semestre numa disciplina do $3^{\circ}$ ano da licenciatura em educação básica. A formação destes professores debate-se com dilemas muito específicos entre os quais avulta o modo separado ou integrado de tratar o conteúdo e a didática. Usando uma metodologia de design research, recorremos a dados de estudos de caso de três formandos apresentando o modo como resolviam tarefas de álgebra, nomeadamente envolvendo sequências pictóricas antes, durante e depois da experiência. Além disso, tendo em vista fazer um balanço global da experiência, descrevemos episódios relevantes do ponto de vista formativo ocorridos durante as aulas. Concluímos que o modo de trabalho exploratório tendo por base situações matemáticas e situações reais da sala de aula, com produções escritas dos alunos e registros em vídeo, e as oportunidades de reflexão e discussão proporcionadas, contribuiu para promover um efetivo desenvolvimento do conhecimento didático das três formandas e do conhecimento matemático da formanda com reduzida formação matemática anterior.
\end{abstract}

Palavras-chave: formação inicial de professores; pensamento algébrico; sequências; generalização; conhecimento didático.

1 Este trabalho é financiado por fundos nacionais através da Fundação para a Ciência e Tecnologia (FCT) no âmbito do Projeto Práticas Profissionais dos Professores de Matemática (contrato PTDC/CPE-CED/0989311/2008). O trabalho, embora da responsabilidade dos autores, é devedor das múltiplas discussões sobre o tema realizadas no seio do projeto.

2 Universidade de Lisboa. Lisboa, Portugal. Alameda Universidade. 1649-004.

3 Escola Superior de Educação de Santarém, Portugal. Complexo Andaluz, 2001-902, Santarém. 


\begin{abstract}
This paper describes an experience carried out in pre-service teacher education, aiming at the development of algebraic thinking of future kindergarten and elementary school teachers, held over a six-month period in a course of the third year of the bachelor's degree in education. Teacher education at this level faces very specific dilemmas, including the separated or integrated treatment of contents and didactics. Using a design research methodology, we applied data from the case studies of three prospective teachers showing how they solved algebra tasks involving pictorial sequences before, during, and after the teacher education experience. In addition, we describe in-class episodes, relevant from the formative point of view, in order to have a global balance of the experience. We concluded that the exploratory work based on mathematical situations and real classroom occurrences, with the students' written productions and video records, and the opportunities for reflection and discussion that arose, have contributed to promote an effective development of the didactic knowledge of the three prospective teachers, and also of the mathematical knowledge of the prospective teacher with less previous mathematics training.
\end{abstract}

Keywords: pre-service teacher education; algebraic thinking; sequences; generalization; didactical knowledge.

\title{
Introdução
}

O interesse pelo desenvolvimento do pensamento algébrico nos primeiros anos de escolaridade tem vindo a ganhar grande expressão. Neste nível, a Álgebra não é entendida como um conjunto de técnicas, mas como um modo de pensar (KIERAN, 2007), possibilitando o surgimento de situações suscetíveis de contribuir para uma compreensão mais aprofundada da Matemática (CANAVARRO, 2007). Para a promoção deste modo de pensar, é essencial proporcionar experiências que envolvem conjeturar, generalizar e justificar usando uma variedade de representações e linguagens (KIERAN, 2011). Esta autora salienta a importância do papel do professor na promoção de ambientes de aprendizagem propiciadores do desenvolvimento do pensamento algébrico dos alunos. Assim, é essencial que o professor tenha em atenção os aspetos matemáticos e didáticos relativos ao ensino da Álgebra de modo a preparar e concretizar situações de aprendizagem que visem esse desenvolvimento. 
A formação inicial de professores dos primeiros anos do ensino básico e de educadores de infância ${ }^{4}$ constitui um suporte fundamental para o desempenho futuro da sua atividade profissional, devendo contemplar experiências formativas que proporcionem o desenvolvimento do conhecimento necessário para esse desempenho. Por isso, é fundamental que os futuros professores, na sua formação inicial, reconheçam a importância do pensamento algébrico neste nível de escolaridade, valorizando a generalização, as relações e o uso de símbolos. A formação inicial deve ter ainda em conta que estes formandos, quando forem lecionar, serão colocados perante desafios relativos ao pensamento algébrico que, na sua maioria, nunca experimentaram enquanto alunos.

Este artigo descreve uma experiência de formação inicial orientada para o desenvolvimento do pensamento algébrico de futuros professores dos primeiros anos que teve lugar numa disciplina de licenciatura. Esta disciplina é orientada pela articulação entre conteúdo e a didática, seguindo uma abordagem exploratória em sala de aula que envolve tarefas matemáticas e a análise de situações da prática do professor e do trabalho dos alunos para a promoção do pensamento algébrico. Em especial, procuramos identificar o contributo desta experiência de formação no desenvolvimento do conhecimento de três formandas relativamente ao ensino da Álgebra nos primeiros anos.

\section{A formação inicial dos professores dos primeiros anos em Álgebra}

De um modo geral, os futuros professores seguem percursos escolares em Matemática bastante distintos, com diferentes experiências de aprendizagem em Álgebra, e revelam diferentes conhecimentos e expectativas em relação ao trabalho neste tema. Por isso, na sua formação inicial, devem ter experiências de aprendizagem que lhes proporcionem o desenvolvimento dos diferentes aspetos do pensamento algébrico (BRANCO; PONTE, 2011; MAGIERA; VAN DEN KIEBOOM; MOYER, 2011).

Os futuros professores devem desenvolver a capacidade de integrar o conhecimento dos conteúdos e processos matemáticos e o conhecimento dos alunos a ensinar, de acordo com a sua escolaridade e as orientações curriculares (PONTE; CHAMPAN, 2008). Estes futuros professores estão inseridos num processo de mudança no ensino-aprendizagem da Álgebra (KAPUT; BLAN-

4 Na continuação deste artigo designamos estes dois grupos simplesmente por "futuros professores". 
TON, 2001), mas muitos deles tiveram poucas experiências com atividades de generalização e formalização enquanto alunos, o que coloca um grande desafio à sua formação inicial. Assim, a sua formação em Álgebra deve proporcionar-lhes experiências de aprendizagem que contribuam para sustentar as suas decisões sobre a aprendizagem dos seus alunos no que respeita ao desenvolvimento do pensamento algébrico.

Os professores dos primeiros anos devem compreender os conteúdos algébricos, compreender como os alunos aprendem e ser capazes de usar estratégias de ensino que fomentem o desenvolvimento do pensamento algébrico dos seus alunos (CAPRARO; RANGEL-CHAVES; CAPRARO, 2008). Os professores devem desenvolver, assim, a sua compreensão do que envolve e o que não envolve o ensino da Álgebra nesta fase de escolaridade (BLANTON et al., 2007). Este ensino, que se designa muitas vezes por early algebra, tem por objetivo ensinar os alunos a pensar algebricamente e iniciá-los no trabalho com símbolos, usando-os para expressar e justificar as suas ideias.

Assim, é fundamental que os futuros professores desenvolvam o seu pensamento algébrico e compreendam o papel da Álgebra nos primeiros anos. Para além disso, é importante que percebam a relação da Álgebra com a Aritmética, de modo a promoverem na sua prática futura o pensamento algébrico dos seus alunos. A este respeito, Billings (2008) sugere que antes de promover o pensamento algébrico nas suas salas de aula, os professores têm de desenvolver uma compreensão pessoal sobre o que significa pensar algebricamente, para o que "precisam de múltiplas experiências de análise da variação, de identificação, representação e generalização de relações entre variáveis” (p. 279). Esta autora considera que as situações com sequências pictóricas crescentes são contextos propícios para promover esta compreensão nos professores, desafiando-os a pensar algebricamente. Este trabalho em torno de sequências pictóricas crescentes permite aos futuros professores percorrer um caminho de compreensão da utilização das variáveis, da procura da generalização e da construção e compreensão de expressões algébricas muito próximo do que deverão percorrer os seus alunos.

\section{A experiência de formação em Álgebra}

O estudo decorre no âmbito de uma disciplina do $3^{\circ}$ ano da licenciatura em Educação Básica, que dá acesso aos mestrados que habilitam para a docência desde a educação pré-escolar ao ensino do $2^{\circ}$ ciclo do ensino básico. A 
experiência de formação segue uma abordagem exploratória, envolvendo os formandos no trabalho a desenvolver e dando relevo aos momentos de discussão e sistematização de conceitos, de modo a proporcionar o desenvolvimento do seu conhecimento sobre Álgebra e o seu ensino. O trabalho na experiência de formação contempla diversos tópicos, como o estudo de relações, regularidades e sequências, funções e modelação matemática, que surgem em sete tarefas. Estas têm o intuito de promover o desenvolvimento do pensamento algébrico dos formandos e a sua reflexão sobre situações concretas de trabalho a realizar com os seus futuros alunos. As situações de ensino-aprendizagem que a experiência de formação proporciona possibilitam: (i) analisar estratégias usadas por alunos; (ii) observar, explorar e relacionar diferentes representações; (iii) compreender que conhecimento os alunos revelam; (iv) identificar eventuais dificuldades dos alunos; e (v) refletir sobre hipóteses de trabalho com os alunos.

Neste artigo, abordamos questões que envolvem a análise e generalização de sequências pictóricas e o trabalho na Tarefa 4 relativa ao visionamento de um vídeo de uma aula de $2^{\circ}$ ano (descrita em Silvestre et al., 2010) em que os alunos trabalham numa tarefa com uma sequência pictórica (Figura 1) que possibilita a análise da prática da professora e das estratégias dos alunos. Aqui, a tecnologia proporciona uma oportunidade de formação significativa para a formação inicial. Llinares e Valls (2009) indicam que o uso de gravações em vídeo de aulas fomenta nos futuros professores a capacidade de analisar e identificar aspetos fundamentais do ensino, dada a possibilidade de relacionarem teoria e prática. Além disso, a análise do que acontece na aula de Matemática contribui para a compreensão por parte dos futuros professores do que será o seu ensino.

Observa a sequência de blocos.

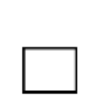

Figura 1

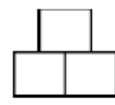

Figura 2

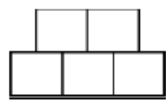

Figura 3

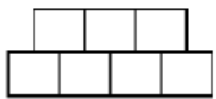

Figura 4

a) Continua a sequência e desenha as figuras 5 e 6 .

b) Quantos peças foram utilizadas para construir cada uma das figuras? Escreve a tua resposta na tabela seguinte.

c) Sem usar desenhos, és capaz de descobrir quantos blocos tem a figura 20 da sequência? Explica como pensaste.

FIGURA 1 - TAREFA COLOCADA AOS ALUNOS DO $2^{\circ}$ ANO 


\section{Metodologia de investigação}

O estudo segue a metodologia de design research, na modalidade de experiência de ensino. O seu objetivo é compreender o processo de desenvolvimento dos formandos proporcionado pela experiência de formação a partir dos pressupostos estabelecidos. Envolve, assim, uma intervenção planeada, concretizada pela segunda autora, que decorre durante todo um semestre e que tem por base uma sequência de episódios de ensino, permitindo analisar a atividade dos participantes (STEFFE; THOMPSON, 2000). Participam os 20 formandos que frequentam a experiência de formação, sendo o percurso de três deles (Alice, Beatriz e Diana) acompanhado de um modo particular. Trata-se de formandas com experiências muito diversificadas antes da entrada no ensino superior e que pretendem frequentar distintos mestrados que habilitam para a docência (Quadro 1).

\begin{tabular}{lll}
\hline Formanda & Frequência de Matemática & Mestrado pretendido \\
Alice & Até ao $9^{\circ}$ ano & Educação Pré-Escolar \\
Beatriz & Até ao $10^{\circ}$ ano & Educação Pré-Escolar e Ensino do $1^{\circ}$ ciclo \\
Diana & Até ao $12^{\circ}$ ano & Ensino do $1^{\circ}$ e do $2^{\circ}$ ciclo \\
\hline QUADRO $1-$ CARACTERIZAÇÃO DAS FORMANDAS QUANTO À FREQUENCIA NA \\
& $\begin{array}{l}\text { DISCIPLINA DE MATEMÁTICA NO ENSINO BÁSICO E SECUNDÁRIO E } \\
\text { AO MESTRADO EM QUE PRETENDE INGRESSAR }\end{array}$
\end{tabular}

A recolha de dados tem por base: (i) dois questionários que envolvem tarefas de natureza algébrica e questões didáticas (um antes da experiência, Q1, e outro após a sua conclusão, Q2); (ii) três entrevistas com as três formandas (duas entrevistas com base nos questionários inicial e final, E1 e E3 respetivamente, e uma outra entrevista, E2, realizada durante a experiência); (iii) observação participante pela docente; e (iv) documentos produzidos durante as entrevistas, na realização das tarefas durante a experiência e no âmbito da elaboração de um portefólio reflexivo sobre o trabalho desenvolvido.

Neste estudo são apresentados dados do trabalho de Alice, Beatriz e Diana na questão 3 da Tarefa 4 e em três questões que envolvem a análise de sequências pictóricas (determinação de termos próximos e distantes e de um termo geral) em três momentos, antes da experiência de formação (Figura 2), durante a experiência de formação (Figura 3), depois da experiência de formação (Figura 4). 

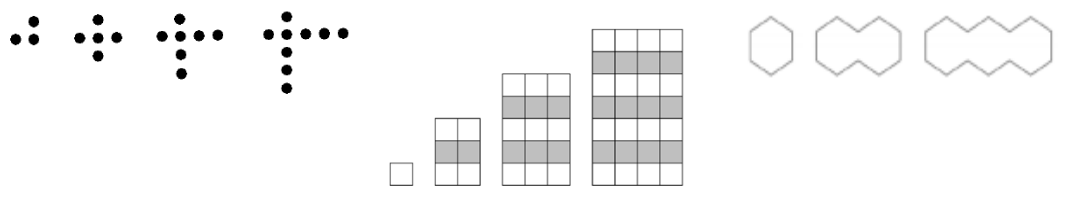

FIGURA 2 - SEQUÊNCIA DO FIGURA 3 - SEQUÊNCIA DA FIGURA 4 - SEQUÊNCIA QUESTIONÁRIO INICIAL SEGUNDA ENTREVISTA DO QUESTIONÁRIO FINAL (Q1-6)

(E2-3)

(Q2-6)

Os dados evidenciam aspetos significativos das situações vividas pelos participantes. A sua análise assume um cunho essencialmente interpretativo de modo a identificar o contributo desta experiência para o desenvolvimento do pensamento algébrico dos participantes e do seu conhecimento sobre o ensino da Álgebra nos primeiros anos. É realizada uma análise de conteúdo de modo a identificar com que frequência surgem determinados objetos.

\section{Alice}

Esta formanda pretende ser educadora de infância e a sua preparação em Matemática limita-se ao $9^{\circ}$ ano.

Antes da experiência de formação. No questionário inicial, Alice associa quatro palavras ao ensino-aprendizagem da Álgebra: Matemática, Raciocínio, Números e Interpretação. Estas palavras estão associadas à Matemática de um modo geral, pois, como indica nessa entrevista, desconhece o que é a Álgebra.

$\mathrm{Na}$ análise da sequência pictórica do questionário inicial, Alice representa corretamente os dois termos a seguir aos representados, por um processo recursivo, acrescentando duas pintas à figura anterior. Para determinar o número de pintas do $60^{\circ}$ termo, adiciona dois à ordem do termo, obtendo como resultado 62 pintas. $\mathrm{Na}$ entrevista, questionada sobre a validade da sua resposta, concretiza este raciocínio para os primeiros termos da sequência representados e verifica para o caso do $2^{\circ}$ termo que a sua conjetura não se verifica. Identifica, então, a parte que se mantém inalterada na constituição de cada termo, constituída por 3 pintas, que respeita ao primeiro termo. Contudo, não consegue indicar o que deve acrescentar a este para obter o $60^{\circ}$ termo e desiste de procurar uma resposta correta.

A generalização que estabelece tem por base um raciocínio recursivo em que $n$ representa o termo anterior e não a ordem do termo. Na entrevista esclarece esta interpretação indicando que "é n mais dois, porque é... É sempre 2 
que acrescenta. É sempre qualquer coisa mais dois" (E1). Nesta questão revela estabelecer apenas uma generalização aritmética.

Durante a experiência de formação. Relativamente à sequência pictórica da segunda entrevista, Alice explica oralmente o modo como interpreta a constituição de cada termo e como a relaciona com a ordem do termo, começando por referir que "a base é sempre o número da ordem" (E2). De seguida, centra a sua análise no termo de $2^{\mathrm{a}}$ ordem. Relaciona a sua altura de três unidades com a sua ordem, referindo ser "número da ordem mais um" (E2). Este raciocínio é válido para o $2^{\circ}$, termo mas não para os restantes. Refaz a sua análise e identifica uma relação entre a ordem e o número de linhas do termo que verifica ser válida para os restantes termos representados:

Alice - $E$ E $n+n-1$. [Referindo-se a altura do termo (Figura 5)]

Investigadora $-n+n-1$, por quê?

Alice - Porque se né $2 \ldots$ Se tivesse aqui [no $2^{\circ}$ termo] mais n era mais 2, mas aqui tem menos 1 [que $n+n$ ]. Aqui [no $3^{\circ}$ termo] é a mesma coisa. 3 [aponta para as primeiras três linhas] é $\mathrm{n}$, porque depois se tivesse mais $\mathrm{n}$ era mais 3, menos 1 vai dar esse [o número restante de linhas] (E2). [Alice escreve $n+n-1$ ]

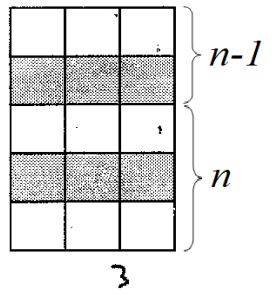

FIGURA 5 - RESOLUÇÃO DE ALICE, E2-3

Por fim, Alice escreve uma expressão para o termo geral, tendo em conta a disposição retangular dos termos. Estabelece, assim, uma generalização algébrica para a sequência que tem por base a constituição dos termos pictóricos que representa em linguagem algébrica.

$\mathrm{Na}$ análise do vídeo da Tarefa 4 da experiência de formação, o grupo de Alice escreve em linguagem algébrica o que alguns alunos indicam em linguagem natural quando determinam termos distantes, expressando simbolicamente as relações que os alunos estabelecem entre a ordem e o número de quadrados do termo (Figura 6). 
- $2 n-1 \rightarrow$ Alquns olunos funravam a linha de quadrados de eima mais a de baixo
- nas eomo a linha de eimatem seuper menos 1 quadrado, ao total
da adicá refirom sempre 1 quadrado. FIGURA 6 - RESOLUÇÃO DO GRUPO DE ALICE, T4

Para Alice foi importante observar a sala de aula, o modo de trabalho dos alunos, as estratégias que estes usam para determinar termos distantes e o modo como conseguem expressar uma generalização. Indica ter ficado surpreendida por os alunos do $2^{\circ}$ ano conseguirem generalizar. Recorda, particularmente, a estratégia de um aluno que usa o seu conhecimento dos números para encontrar uma regra geral para determinar um termo da sequência numérica. A análise desta situação de ensino-aprendizagem contribuiu para que conseguisse concretizar o trabalho que os alunos podem desenvolver e as potencialidades de estabelecer generalizações a partir destes contextos. Refere que os alunos "podem relacionar conceitos, como é o caso acho que era do Bruno que era o dobro, punha o dobro e tirava um" (E2).

Após a experiência de formação. No questionário final, Alice continua a referir apenas palavras bastante gerais que associa ao ensino-aprendizagem da Álgebra: Raciocínio, Expressões, Números e Matemática. Na terceira entrevista destaca a palavra "expressões", pois, ao recordar o seu escasso conhecimento inicial em Álgebra, considera ter agora um maior conhecimento sobre expressões, tanto numéricas como algébricas.

$\mathrm{Na}$ interpretação de termos pictóricos próximos na sequência do questionário final, Alice acrescenta sucessivamente figuras idênticas ao $1^{\circ}$ termo para obter os termos seguintes, retirando dois segmentos. Por exemplo, interpreta o $2^{\circ}$ termo como sendo obtido pela junção de duas figuras iguais ao $1^{\circ}$ termo com um lado adjacente que desaparece. Em seguida, identifica os três primeiros termos da sequência numérica 6,10 e 14, e verifica que de um termo para o seguinte adiciona 4. Relaciona então esta sequência com a sequência dos múltiplos de 4 , verificando ser necessário adicionar 2. Deste modo, determina um termo geral, $4 n+2$, da sequência numérica usando a diferença como fator multiplicativo e ajustando o resultado. Para determinar o $46^{\circ}$ termo, usa o termo geral e, apesar de indicar o valor correto, apresenta apenas a expressão numérica $4 \times 46=186$. $\mathrm{Na}$ entrevista identifica que deveria ter $4 \times 46+2$.

Balanço do trabalho com sequências pictóricas. Antes desta experiência, Alice desconhecia o trabalho com sequências pictóricas. Na segunda entrevista, que ocorre após a realização da Tarefa 4, identifica esse trabalho como sendo o que promoveu nela uma maior aprendizagem e o que mais gostou: "Eu gostei muito, eu gostei muito da generalização. [...] É engraçado ver como a partir de 
uma imagem conseguimos descobrir a imagem número não sei quantos" (E2). A realização de generalizações a partir de sequências pictóricas, permitindo determinar termos de ordem distante, surpreende-a e é um tópico que gosta de tratar, mesmo reconhecendo ter sentido dificuldades em algumas situações. Demonstra confiança no seu conhecimento a respeito deste assunto, em particular na determinação de um termo geral de uma sequência numérica associada a uma sequência pictórica, procurando regularidades, pois, como disse, "tem de haver alguma relação com o número de ordem e depois a partir do número de ordem vou por hipóteses" (E2).

Alice refere à importância das crianças contactarem com diversos aspetos da Matemática de modo a promover o desenvolvimento do seu raciocínio. Refere que, para isso, o professor deve "levar a que eles consigam pensar ainda que numa coisa simples, porque não pode ser uma coisa complicada. Eles já têm que pensar, já têm que experimentar então já os leva a raciocinar" (E3). Tendo como horizonte a educação pré-escolar, indica as sequências, repetitivas e crescentes, como um tópico que pode trabalhar. A evolução que manifesta na compreensão deste tipo de situação e a segurança que revela nos conhecimentos desenvolvidos na experiência de formação permitem-lhe dizer que pode adequá-las ao ensino pré-escolar, promovendo o desenvolvimento do raciocínio das crianças.

\section{Beatriz}

Esta formanda pretende seguir um mestrado que tanto lhe permite ser educadora de infância quanto professora do $1^{\circ}$ ciclo e a sua frequência com sucesso em Matemática vai até ao $10^{\circ}$ ano.

Antes da experiência de formação. No questionário inicial, Beatriz não escreve qualquer palavra que associe ao ensino-aprendizagem da Álgebra, indicando, na primeira entrevista, não ter ideia do que isso envolve. Na análise de termos próximos da sequência pictórica crescente do questionário inicial, usa uma abordagem aditiva, indicando que adiciona duas pintas de um termo para o seguinte. Quando determina um termo distante, indica apenas que são necessárias 121 pintas, não apresentando uma justificação por escrito. $\mathrm{Na}$ entrevista, esclarece ter identificado a relação entre a ordem e o número de pintas correspondente pela análise da sequência numérica. Analisando o $2^{\circ}$ termo, relaciona o termo numérico com o dobro da ordem e atende a que tem 5 pintas e faz o mesmo para o $3^{\circ}$ termo, concluindo que tem mais uma pinta que o dobro da ordem: 
Aumenta sempre duas... Para eu ter dito cento e vinte e uma, se aumentava sempre duas, supostamente devia ser cento e vinte, se eu disse que era cento e vinte e um... Um, dois, três, quatro, cinco, o dobro de dois é quatro, e tem cinco, um, dois, três, quatro, cinco, seis, sete, o dobro de três é seis e tem uma a mais (E1).

A partir da identificação desta regularidade, indica em linguagem natural a generalização: "Tenho o dobro do termo, mais um" (E1). Por vezes revela ainda alguma confusão no que respeita à utilização do vocabulário "termo" e "ordem".

No questionário, escreve uma expressão algébrica para determinar um termo de qualquer ordem, $n \times 2+1$. É com base na generalização que expressa em linguagem natural que justifica essa expressão algébrica: "Se n é o termo, e eu aqui estou a dizer que o termo dois tem o dobro mais 1. Se temos o termo n, temos o n vezes dois que é o dobro do termo, mais l" (E1). Ao apresentar respostas corretas, Beatriz mostra compreender a sequência e conseguir generalizar algebricamente ao representar uma regra geral em linguagem algébrica.

Durante a experiência de formação. Na segunda entrevista, Beatriz indica que a expressão algébrica que expressa a área dos termos é de $2^{\circ}$ grau ao verificar que a primeira diferença entre termos consecutivos não é constante e que a diferença entre essas diferenças, a segunda diferença, é constante e igual a 4. Começa por ter alguma dificuldade em determinar o termo geral desta sequência, mas consegue dar diversas indicações relativamente a algumas regularidades. Além de verificar que a segunda diferença é constante, associa o número de quadrados de cada termo pictórico à sua disposição retangular, exemplificando

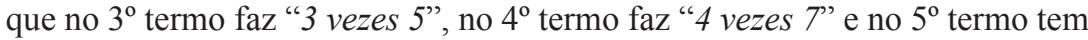
"5 vezes 9". Relaciona, assim, a disposição retangular com a ordem em cada termo, como indica para o $4^{\circ}$ termo "isto é 4 mais 3 , vezes 4 " e para o $5^{\circ}$ termo "5 mais 4, vezes 5". Representa esta relação por um termo geral que estaria correto caso incluísse os parêntesis a indicar a realização da adição em primeiro lugar que Beatriz considera quando se expressa oralmente relativamente à regra geral que considera: "n mais n menos 1, vezes n" (E2) (Figura 7).

$\mathrm{Na}$ segunda entrevista, Beatriz salienta o contributo do trabalho com sequências para o estabelecimento de generalizações a partir da determinação de termos distantes, logo desde os primeiros anos. Para isso contribuiu o trabalho realizado na Tarefa 4 , no que respeita à análise de um episódio de sala de aula

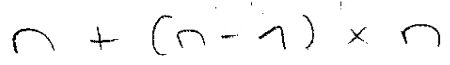

FIGURA 7 - EXPRESSÃO ALGÉBRICA DE BEATRIZ, E2-3 
com alunos do $2^{\circ}$ ano que determinam termos próximos e distantes de uma sequência pictórica, tendo mesmo generalizado a sequência numérica que lhe está associada em linguagem verbal. Identifica que "os alunos olharam e interpretaram a sequência" (Portefólio, T4) de diferentes modos. Neste documento, salienta a situação que envolve a adição do número da ordem com o número natural que o antecede, que constitui uma generalização contextualizada, pois, como refere, os alunos recorrem sempre a um exemplo para expressá-la:

Substituiu os blocos por números e fez que para a figura dois, o 1 está em cima e o 2 está em baixo, na figura três, o 2 que estava em baixo na figura anterior passou para cima na figura seguinte, ficando o 3 por baixo [...] Assim, para a figura 20 a criança pensou: o 19 que está por baixo na figura anterior, passa para cima na figura seguinte e por baixo deste 19, fica o 20, se somarmos o 19 com o 20, obtemos o número de blocos da figura 20 que é igual a 39 (Portefólio, T4).

Após a experiência de formação. No questionário final indica cinco palavras relacionadas ao ensino-aprendizagem da Álgebra, referindo a capacidade de "generalizar", bem como tópicos e conceitos específicos de Álgebra como "sequências", "funções", "incógnitas" e "termo geral". Na terceira entrevista salienta o facto de já conseguir conceber o trabalho da Álgebra nos primeiros anos do ensino básico, o que não acontecia antes de frequentar a experiência de formação.

Na sequência pictórica do questionário final, Beatriz indica o termo geral, $4 n+2$, logo na primeira questão. Na terceira entrevista justifica a expressão algébrica apresentada com base na relação entre a ordem e o termo numérico. Confirma que a expressão está correta com base nos primeiros termos: " 4 vezes 1, 4. Mais 2, $6 \ldots$... vezes 2, 8. Mais 2, 10" (E3). Usa a expressão algébrica para determinar o termo distante pedido, o $46^{\circ}$ termo. Atribui a $n$ o valor 46 e efetua os cálculos, obtendo como resultado 186 segmentos. Revela, assim, facilidade em determinar o termo geral da sequência e usa-o corretamente para determinar termos da sequência dada a ordem.

Balanço do trabalho com sequências pictóricas. Na segunda entrevista, Beatriz faz um balanço do trabalho já desenvolvido. Nesse momento da experiência de formação refere ter apreciado particularmente o trabalho com sequências pictóricas e numéricas, isto porque gosta do desafio e do facto de as situações exigirem que raciocine para encontrar um termo geral que depois lhe permite encontrar termos de diferentes ordens. Apesar de considerar que consegue 
determinar o termo geral tanto de sequências numéricas quanto de sequências pictóricas, diz preferir explorar estas últimas, pois nestas pode "relacionar só a ordem e a imagem, e conseguir visualizar, mais do que... Se calhar tenho de fazer um esforço maior para encontrar o termo geral se tiver só números do que se tiver sequências pictóricas" (E2).

$\mathrm{O}$ visionamento do vídeo de sala de aula com os alunos de $2^{\circ}$ ano permite a Beatriz a identificação de aspetos a trabalhar nos primeiros anos. Em especial, reconhece que o trabalho proporcionado aos alunos com sequências pictóricas possibilita o início do desenvolvimento do pensamento algébrico:

Achei muito importante e interessante termos tomado contacto com um episódio de sala de aula com crianças de $2^{\circ}$ ano, pois pudemos observar a forma como as crianças pensam, e apesar de ainda não lhes ter sido ensinada a Álgebra, esta já lhes está interiorizada inconscientemente, dai uma das crianças ter referido o "segredo" [refere-se a um termo geral] (Portefólio, T4).

Beatriz verifica que os alunos conseguem generalizar e expressar essa generalização em linguagem verbal logo nos primeiros anos do ensino básico.

\section{Diana}

Esta formanda pretende seguir um mestrado que lhe permite ser professora do $1^{\circ}$ e do $2^{\circ}$ ciclo e a sua preparação em Matemática vai até ao final do ensino secundário $\left(12^{\circ}\right.$ ano $)$.

Antes da experiência de formação. No questionário inicial, Diana revela conhecer os tópicos centrais do ensino da Álgebra no $3^{\circ}$ ciclo e ensino secundário, as funções e as equações. Identifica, assim, aspetos gerais relativos à Álgebra, mas reconhece que não serão estes os tópicos a trabalhar nos primeiros anos, pelo menos do modo formal como os aprendeu. Escreve ainda "ensino da Matemática" e "aprendizagem da Matemática", revelando associar o ensino-aprendizagem da Álgebra, de um modo geral, ao ensino-aprendizagem da Matemática.

Diana analisa a sequência pictórica do questionário inicial, estabelecendo uma relação entre o número de pintas na vertical e na horizontal e o total de pintas. Representa por $x$ o número de pintas de cada uma das filas e por 
$2 x-1$ o número total de pintas, reconhecendo que as duas filas têm uma pinta comum: "Em qualquer uma das sequências há 2 filas, uma na vertical, outra na diagonal, as duas com o mesmo número de pintas $[x]$, ou seja, 2x, depois, como possuem uma pinta em comum fica $2 x-1$ " (Q1-6). Usa também esta relação para determinar o termo de ordem 60 , para o qual indica a expressão $2 \times 61-1=121$. Contudo, não explicita a relação existente entre a ordem da figura e a sua constituição. Na entrevista, quando esclarece o modo como determina este termo, estabelece, então, a relação entre a ordem e o número de pintas em cada fila " $x=n+1$, portanto 60 vai ser... O x vai ser igual a $60+1$. Agora aqui já tenho qual é que é $\mathrm{x}$ e agora aqui vou substituir na... [expressão]" (E1).

Diana não apresenta ainda uma expressão que relacione diretamente a ordem com o número de pintas. Relaciona o número total de pintas com o número de pintas na fila e este último com a ordem. Generaliza a situação e representa-a em linguagem algébrica, revelando usar a simbologia algébrica com alguma facilidade.

Durante a experiência de formação. Na sequência pictórica da segunda entrevista, Diana analisa os termos e determina rapidamente o termo geral da sequência numérica associada com base na disposição retangular dos termos pictóricos e na relação que estabelece entre cada uma das dimensões do retângulo e a sua ordem na sequência (Figura 8).

Então..., acho que está bem [a expressão]. Então nós ... O n por quê? n porque se nós formos ver a largura dos retângulos, vai ser sempre $\mathrm{n}, o$ número de quadrados o $\mathrm{n}$. Por exemplo, aqui $\left[1^{\circ}\right.$ termo $]$ tem 1 , aqui $\left[2^{\circ}\right.$ termo] tem 2, aqui [ $3^{\circ}$ termo] vai ter 3, aqui $\left[4^{\circ}\right.$ termo] vai ter 4 . E por ai fora. Portanto vai ser $\mathrm{n}$. Depois vamos ter que... Para saber o número de quadrados vamos ter que multiplicar... O comprimento. Pronto, e o comprimento vai ser $2 n-1$ (E2).

Depois de ter determinado um termo geral $n \times(2 n-1)$, Diana manipula a expressão determinando uma expressão equivalente, $2 n^{2}-n$. Além desta estratégia, diz ser possível, neste caso, determinar o termo geral com base na sequência numérica e nas diferenças entre termos consecutivos, sendo a segunda diferença constante e igual a 4. Com base nesta informação confirma "ser uma expressão do tipo $a n^{2}+b n+c "$ (E2). Contudo, reconhece que este método se pode tornar mais complexo e que "é muito mais simples" partir dos termos pictóricos, "mesmo para as crianças" (E2). Estabelece rapidamente, a partir da 


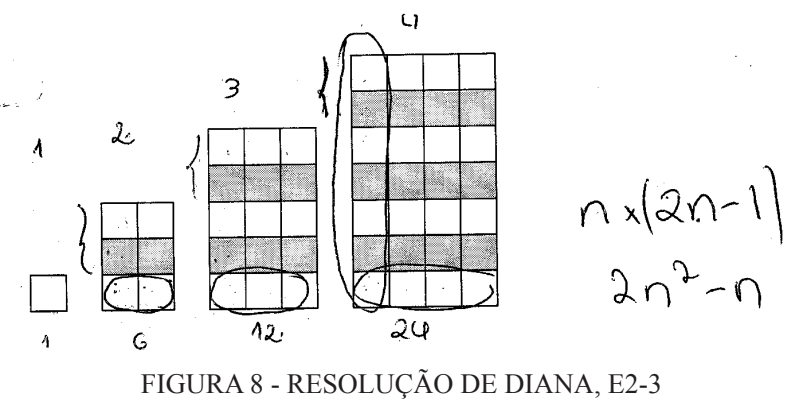

análise dos termos pictóricos, uma relação entre a constituição e cada termo e a sua ordem, realizando uma generalização algébrica que representa por duas expressões algébricas equivalentes.

Com base nesta situação de sala de aula analisada na Tarefa 4 e no trabalho de análise de sequências pictóricas e numéricas que desenvolve na experiência de formação, Diana sugere que para os alunos dos primeiros anos "é mais fácil para eles trabalharem em sequências pictóricas do que com sequências numéricas" (E2). Indica que nestes anos de escolaridade os alunos podem não usar a linguagem algébrica, mas, ainda assim, faz sentido trabalharem estas questões para determinarem termos próximos e distantes, pois descrevem relações em situações contextualizadas, como exemplifica:

Com linguagem algébrica mesmo não, eu acho que poderão chegar lá, por exemplo, se nós perguntarmos o termo, o termo mais próximo, acho que eles conseguem. Como foi o caso de ontem [referindo-se ao vídeo]. [...] Eles sabiam que em cima tinha sempre menos 1, logo quando era 50 eles tiravam 1, punham 49, e em baixo punham 50. Ai conseguem, eles estão a fazer isso sem dar por isso ao fazerem o $n-1+n$.

Diana verifica que a generalização que os alunos estabelecem é algébrica apesar de estes não usarem a linguagem algébrica para expressá-la: "Eles, sem darem por isso, estavam a fazer, mas não escreveram. Não escreveram a expressão em si" (E2).

Para Diana é importante que os alunos analisem termos próximos e termos distantes para "verem a relação que a ordem tem com os termos. Acho que é mesmo isso, a relação, compararem... Eles compararem qual é a relação que 
têm e se compreenderem os primeiros casos também vão conseguir compreender mais [distantes]" (E2). Na sua perspetiva, a procura de termos de ordem distante promove o estabelecimento dessa relação mais que a indicação de termos muito próximos porque, "por exemplo, aqui na quarta, o que provavelmente eles iriam fazer era fazer o desenho e contarem e não perceberem qual era mesmo a relação que tinha, o que é que havia a mais, a menos" (E2). Deste modo, identifica que, para ordens próximas, os alunos podem privilegiar uma estratégia de representação e contagem e não chegar a estabelecer a generalização algébrica. Com a determinação de termos distantes, a primeira estratégia não se torna eficaz, sendo, por isso, mais propícia ao surgimento da generalização.

Após a experiência de formação. No questionário final, todas as palavras indicadas por Diana estão relacionadas ao ensino da Álgebra e abrangem diversos tópicos. Em primeiro lugar escreve "pensamento algébrico" e, em seguida, indica quatro palavras relativas a tópicos e conceitos específicos da Álgebra "variável independente e dependente", "sucessões", "sequências" e "funções". $\mathrm{Na}$ entrevista, salienta o facto de agora conseguir conceber o início do trabalho no âmbito da Álgebra nos primeiros anos do ensino básico, o que não acontecia antes de frequentar a experiência de formação.

Na sequência pictórica do questionário final, Diana responde corretamente a todas as questões. Na determinação de termos próximos usa expressões numéricas que revelam a sua análise dos termos pictóricos em diferentes partes, as que variam com a ordem e as que são constantes. Para o $4^{\circ}$ termo calcula o número de segmento pela expressão $4 \times 2+4 \times 2+2=18$ e, de modo semelhante, determina o número de segmentos do $5^{\circ}$ termo, $5 \times 2+5 \times 2+2=22$. Para determinar o $46^{\circ}$ termo, encontra um termo geral da sequência numérica com base na análise da constituição dos termos pictóricos, relacionando o número de segmentos de cada termo com a sua ordem (Figura 9). Considera que tem a ordem $x$ e que nessa ordem tem $x$ vértices em cima e $x$ vértices em baixo, sendo que para cada vértice tem dois segmentos: " $2 \mathrm{x}$, porque eram os dois de cima. Ou seja, era 2 vezes $\mathrm{x}$ mais $2 \mathrm{x}$, porque eram os de baixo... Mais 2, porque são os das pontas" (E3):

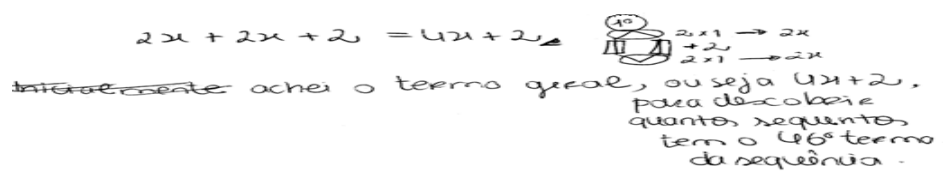

FIGURA 9 - RESOLUÇÃO DE DIANA, Q2-6B

Diana faz um esquema para o $1^{\circ}$ termo que ilustra o modo como decompõe a figura. Deste modo, revela a relação que estabelece entre cada parte (variante 
e invariante) e a ordem, que considera válida para qualquer termo da sequência. Na expressão substitui $x$ por 46 , determinando o termo pedido através da expressão $4 \times 46+2=186$.

Balanço do trabalho com sequências pictóricas. As situações que envolvem sequências pictóricas são significativas para a aprendizagem de Diana e para o desenvolvimento da sua compreensão da Matemática. Destaca o facto de a experiência de formação lhe proporcionar "perceber o porquê" dada a grande ênfase posta na justificação:

Nós tínhamos de mostrar a expressão e temos de perceber o porquê da expressão e temos de justificar. [...] Era explicar o porquê, nós muitas vezes fazíamos [antes da experiência de formação], chegávamos à fórmula e muitas vezes não percebíamos o porquê, chegávamos lá e estava feito. Era aquilo que era preciso e estava feito. Agora é perceber o porquê e perceber através da fórmula que já temos que se dividirmos a expressão poderemos chegar e explicar a imagem de outra maneira ... Há diferentes maneiras de ver a imagem [termo da sequência] [...] E chegamos a várias expressões que, depois no fim, dão o mesmo, mas podemos trabalhar a imagem de diferentes maneiras, e isso ainda eu não tinha feito (E2).

Ao promover a análise da sequência pictórica e de diferentes expressões algébricas para expressar a generalização de sequências numéricas que lhes estão associadas, a experiência de formação proporciona a Diana uma aprendizagem diferente da realizada anteriormente em Álgebra. Refere, ainda, a importância do visionamento do vídeo de sala de aula para a sua compreensão do trabalho que os alunos conseguem desenvolver, das suas estratégias e capacidades. Além disso, reconhece a importância do trabalho que se propõe aos alunos de modo a proporcionar situações de sala de aula semelhantes à visionada em que se fomenta a generalização. Considera que o bom desempenho que se verifica e o seu envolvimento deve advir de um trabalho regular com situações de exploração por parte dos alunos.

\section{Discussão e conclusão}

O estudo evidencia que o trabalho desenvolvido promove nos formandos a compreensão de diferentes modos de obter generalizações com base na identificação de regularidades, que a maioria expressa simbolicamente por meio de 
relações diretas, como acontece com Alice, que tem por base a diferença entre termos consecutivos e faz o ajuste correto, Beatriz, que identifica regularidades na sequência numérica, e Diana, que decompõe os termos pictóricos relacionando as partes à sua ordem. No final da experiência de formação, as três formandas generalizam e expressam essas generalizações em linguagem algébrica para usar as expressões algébricas no cálculo do termo distante.

$\mathrm{O}$ estudo mostra que a abordagem exploratória contribui para que formandos como Alice, que nunca tinham trabalhado com sequências pictóricas, generalizem e expressem simbolicamente as generalizações. Antes da experiência de formação, esta formanda estabelece apenas generalizações aritméticas, não conseguindo determinar termos distantes e um termo geral. No final, tem uma interpretação adequada da diferença entre dois termos consecutivos, que usa para determinar um termo geral da sequência, estratégia que outros estudos identificam em alunos (e.g., BARBOSA, 2011). Também para formandos como Beatriz e Diana, que já antes da experiência de formação conseguem formular generalizações, o trabalho realizado tem um contributo importante no que respeita à compreensão da utilização da simbologia algébrica e do significado da variável, conhecimento importante para o professor dos primeiros anos, como reconhece Billings (2008).

Tal como referem Llinares e Valls (2009), também este estudo mostra que a análise de vídeos permite identificar aspetos fundamentais do ensino, em particular no que respeita à capacidade de generalização dos alunos e ao modo como expressam as generalizações, bem como a importância de um trabalho sistemático com vista ao desenvolvimento do pensamento algébrico e o papel do professor. Beatriz valoriza esta oportunidade de aprendizagem pela possibilidade de analisar os diferentes modos de os alunos olharem para a sequência pictórica. Todas as formandas ficam surpreendidas com o facto de estes conseguirem generalizar a sequência pictórica e com isso determinar termos distantes.

Os formandos revelam conhecimentos muito distintos antes da experiência de formação. Inicialmente, Alice revela muitas dificuldades e é evidente uma melhoria no seu conhecimento matemático. Reconhece que o conhecimento que a experiência de formação lhe proporciona vai além do que necessita para lecionar no nível pré-escolar e valoriza as aprendizagens que realizou. Para Beatriz, o contributo da experiência de formação respeita mais ao desenvolvimento do seu conhecimento didático. No final compreende melhor o trabalho a realizar com os alunos e a prática do professor, ficando com expetativas elevadas relativamente à aprendizagem dos alunos no $1^{\circ}$ ciclo. Pelo seu lado, Diana, que também revela um bom conhecimento matemático desde o início, desenvolve a sua compreensão dos conceitos e dos próprios procedimentos, bem como do trabalho a 
realizar nos primeiros anos, deixando de entender a Álgebra apenas associada ao cálculo, perspetiva que tinha desenvolvido enquanto aluna do ensino básico e secundário. Esta formanda reconhece que desenvolveu a sua compreensão das estruturas matemáticas, entendendo agora o porquê de uma situação quando antes o seu conhecimento respeitava ao como resolver as situações, aspeto que Zaskis et al. (2011) consideram como importante para o desenvolvimento dos futuros professores. Estando no início da experiência de formação mais focada no ensino do $2^{\circ}$ ciclo, revela no final uma melhor compreensão do ensino no $1^{\circ}$ ciclo, em particular no que respeita à concretização de situações que visam o desenvolvimento do pensamento algébrico dos alunos.

Nesta experiência de formação, a articulação entre pedagogia e conteúdo (sublinhada por Ponte e Chapman, 2008) revela-se significativa para o desenvolvimento do conhecimento matemático dos formandos, bem como do conhecimento do ensino da Álgebra nos primeiros anos. O estudo das sequências e a importância da generalização ganharam todo o sentido tendo em vista o trabalho a realizar com os futuros alunos dos primeiros anos, cujos contornos os formandos puderam perceber com clareza. A identificação das estratégias dos alunos e dos processos de trabalho do professor mostrou também a necessidade de uma efetiva compreensão matemática dos tópicos que se pretende ensinar. Assim, o trabalho de cunho didático dá relevância ao conhecimento matemático e o trabalho em Matemática é orientado para o exercício profissional, ganhando um novo sentido.

\section{REFERÊNCIAS}

BARBOSA, A. Generalização de padrões em contextos visuais: um estudo no $6 .^{\circ}$ ano de escolaridade. In: MARTINHO, M. H.; FERREIRA, R. A.; VALE, I.; PONTE, J. P. (Eds.). Ensino e aprendizagem da álgebra. Atas do EIEM 2011. Póvoa do Varzim: APM, 2011. p. 327-345. Disponível em: <cmup.fc.up.pt/cmup/eiem/grupos/documents/19.Barbosa. pdfs. Acesso em: 7/11/2013.

BILLINGS, E. Exploring generalization through pictorial growth patterns. In: GREENES, C.; RUBENSTEIN, R. (Eds.). Algebra and algebraic thinking in school mathematics. Reston: NCTM, 2008. p. 279-293.

BLANTON, M.; SCHIFTER, D.; INGE, V.; LOFGREN, P.; WILLIS, C.; DAVIS F.; CONFREY, J. Early algebra. In: KATZ, V. J. (Ed.). Algebra: gateway to an technological future. MAA Report. Washington, D.C.: The Mathematical Association of America, 2007. p. 7-14. 
BRANCO, N.; PONTE, J. P. Situações de modelação na formação inicial de professores. In: MARTINHO, M. H.; TOMÁS FERREIRA, R. A.; VALE, I.; PONTE, J. P. (Orgs.). Ensino e aprendizagem da Álgebra: Actas do EIEM 2011. Póvoa do Varzim: APM, 2011. p. 383-403. Disponível em: <http://cmup.fc.up.pt/cmup/eiem/grupos/documents/22. Branco-Ponte.pdf $>$. Acesso em: 7/11/2013.

CANAVARRO, A. P. O pensamento algébrico na aprendizagem da Matemática nos primeiros anos. Quadrante, Lisboa, v. 16, n. 2, p. 81-118, 2007.

CAPRARO, M. M.; RANGEL-CHAVEZ, A.; CAPRARO, R. M. Effective preparation for teaching of algebra at the primary level. In: MEETING OF THE INTERNATIONAL CONGRESS ON MATHEMATICAL EDUCATION, 11., 2008, Monterrey. Annals... Monterrey: ICMI, 2008. Disponível em:<http://tsg.icme11.org/document/get/382>. Acesso em: 1/3/2013.

KAPUT, J.; BLANTON, M. Algebrafying the elementary mathematics experience - part I: transforming task structures. In: STUDY CONFERENCE OF THE INTERNATIONAL COMMISSION ON MATHEMATICS INSTRUCTION: The future of the teaching and learning algebra, 12., 2001, Melbourne. Proceedings... Melbourne: ICMI, 2001. (v. 1, p. 344-351).

KIERAN, C. Developing algebraic reasoning: the role of sequenced tasks and teacher questions from the primary to the early secondary school levels. Quadrante, Lisboa, v. 16, n. 1, p. 5-26, 2007.

. Overall commentary on early algebraization: Perspectives for research and teaching. In: CAI, J.; KNUTH, E. (Eds.). Early algebraization. Berlin: Springer, 2011. p. 579-593.

LLINARES, S.; VALLS, J. The building of pre-service primary teachers' knowledge of mathematics teaching: interaction and online video case studies. Instructional Science, Springer, New York, v. 37, n. 3, p. 247-271, May 2009.

MAGIERA, M.; VAN DEN KIEBOOM, L.; MOYER, J. Relationships among features of pre-service teachers' algebraic thinking. In: CONFERENCE OF THE INTERNATIONAL GROUP OF PSYCHOLOGY OF MATHEMATICS EDUCATION, 35., 2011, Ankara. Proceedings... Ankara: PME, 2011. (v. 3, p. 169-176).

PONTE, J. P.; CHAPMAN, O. Preservice mathematics teachers' knowledge and development. In: ENGLISH, L. (Ed.). Handbook of international research in mathematics education. 2. ed. New York: Routldge, 2008. p. 225-263.

SILVESTRE, A.; FARIA, A.; SOUSA, H.; CRISTO, I.; SANTOS, I.; MOLARINHO, M. J.; VELADAS, M. Sequências pictóricas: estratégias de generalização dos alunos de $2 .^{\circ}, 3 .^{\circ}$ e $5 .^{\circ}$ anos. In: GTI (Org.). O professor e o programa de matemática. Lisboa: APM, 2010. p. 89-119. 
STEFFE, L.; THOMPSON, P. Teaching experiment methodology: underlying principles and essential elements. In: LESH, R.; KELLY, A. (Eds.). Research design in mathematics and science education. Hillsdale: Erlbaum, 2000. p. 267-307.

ZASKIS, R.; LEIKIN, R.; JOLFAEE, S. C. Contributions of "mathematics for elementary teachers" courses to teaching: prospective teachers' views and examples. MERGA, Mathematics Teacher Education and Development, v. 13, n. 2, p. 3-21, 8 dez. 2011. Disponível em $<$ http://www.merga.net.au/documents/MTED_13_2_Zazkis_Leikin_Jolfaee. pdf $>$. Acesso em: 8/8/2013.

Texto recebido em 08 de agosto de 2013.

Texto aprovado em 10 de setembro de 2013 